\title{
Qualidade de produtos orgânicos: a percepção dos produtores de hortaliças de uma feira ecológica em Porto Alegre - RS
}

\author{
Organic products quality: vegetable growers perception at an Ecological Fair in Porto Alegre - RS \\ Joice Zagna Valent' ${ }^{1}$, Sirlei Tonello Tisott ${ }^{2}$, Verônica Schmidt ${ }^{3}$, Vinicius Dornelles Valent ${ }^{4}$ \\ ' Mestre em Agronegócios, Universidade Federal do Rio Grande do Sul, Porto Alegre, Brasil. \\ 2 Doutoranda em Agronegócios, Universidade Federal do Rio Grande do Sul, Porto Alegre, Brasil. \\ ${ }^{3}$ Profa. Dra. do Departamento de Medicina Veterinária Preventiva, Universidade Federal do Rio Grande do Sul, Porto Alegre, Brasil. \\ ${ }^{4}$ Mestre em Administração, Universidade Federal do Rio Grande do Sul, Porto Alegre, Brasil.
}

\begin{abstract}
Resumo
O uso de práticas agrícolas sustentáveis promove a preservação dos recursos naturais. Especificamente, a produção orgânica de alimentos destaca-se entre estas ações. Neste contexto, a fundamentação teórica utilizada abordou a produção agroecológica de alimentos, a cooperação na agricultura orgânica e a percepção da qualidade na produção orgânica de alimentos. Assim, o objetivo geral foi identificar os parâmetros de qualidade adotados pelos produtores de hortaliças da feira ecológica de Porto Alegre, Rio Grande do Sul. Esta pesquisa é do tipo aplicada e classificada como exploratória, com uma abordagem quantitativa e qualitativa de tratamento dos dados. Os resultados demonstraram que, para a maioria dos produtores rurais, uma hortaliça de qualidade está atrelada somente à produção orgânica. Para garantir a qualidade, salienta-se que cuidados devem ser tomados nos principais elos da cadeia produtiva..
\end{abstract}

Palavras-chave: Agroecologia. Produção orgânica. Qualidade. Hortaliças.

\begin{abstract}
The use of sustainable agricultural practices promotes natural resources conservation. Specifically, organic foods production stands out among these actions. In this context, the theoretical framework used addressed the agroecological foods production, cooperation on organic agriculture and the perception of quality in organic foods production. Thus, the overall goal was to identify quality parameters adopted by farmers at an Ecological Fair in the city of Porto Alegre, Rio Grande do Sul. This is an applied type research and classified as exploratory with quantitative and qualitative approaches for data processing. The results showed that, for most farmers, a vegetable quality is linked only to organic production. To ensure quality, we emphasize that care must be taken throughout in production chain main links.
\end{abstract}

Keywords: Agroecology. Organic production. Quality. Greenery 


\section{INTRODUÇÃO}

O aumento na exigência dos consumidores por alimentos de qualidade e sem produtos químicos, e a busca por uma agricultura ambientalmente sustentável alavancou o desenvolvimento da produção de alimentos orgânicos. Neste sistema de produção existe a preocupação com o uso do solo e com a saúde do consumidor. Ademais, proporciona uma vida mais saudável aos agricultores e, até mesmo, melhores condições financeiras, por meio de novos nichos de mercado.

É através da base científica oferecida pela agroecologia que estas práticas são aplicadas. Juntamente com conhecimentos multidisciplinares agregados a saberes populares e tradicionais, a agroecologia é uma ciência integradora que se preocupa com a preservação ambiental e a qualidade de vida humana, acima de tudo. Para Andrioli (2007), a agroecologia, como princípio de sustentabilidade da agricultura familiar, remete-nos a uma economia ecológica em harmonia com as outras dimensões do desenvolvimento.

Salienta-se que, sendo a agroecologia uma ciência que envolve as práticas sustentáveis de ocupação e uso dos recursos naturais, a produção de alimentos orgânicos se insere nesta prática.

A agricultura orgânica, por sua vez, em função da pequena escala de produção, enfrenta dificuldades na comercialização. Muitos agricultores não possuem transporte próprio para levar os produtos até o ponto de venda. Muitas vezes, estes produtos são acondicionados em lugares pequenos e transportados em veículos impróprios o que pode comprometer a qualidade. Um alimento orgânico, se não for manuseado com cuidado, pode ter sua qualidade comprometida por outros fatores envolvidos na cadeia.

Uma alternativa para esse problema são as associações ou cooperativas agropecuárias, pois oferecem apoio logístico. Além disso, facilitam a comercialização por meio de feiras, fornecimento de produtos para alimentação escolar e outros tipos de contratos. As cooperativas são importantes segmentos do agronegócio brasileiro, representando o trabalho em conjunto e a busca por resultados positivos, o que pode configurar em produtos agrícolas de qualidade.

Diante desse contexto, com um mercado consumidor cada vez mais exigente e preocupado com a qualidade e origem dos produtos, insere-se o seguinte questionamento: quais são os parâmetros de qualidade adotados na produção e comercialização de hortaliças orgânicas, segundo a percepção dos produtores rurais de uma Feira Ecológica de Porto Alegre, no estado do Rio Grande do Sul? Para tanto, o objetivo geral foi identificar estes parâmetros de qualidade adotados pelos produtores de hortaliças desta feira. Os objetivos específicos foram: identificar o perfil dos produtores de hortaliças, identificar as práticas de manejo adotadas por eles, verificar os motivos que os levaram a produzir este tipo de cultura e, por último, entender as definições de qualidade adotadas pelos agricultores.

\section{AGROECOLOGIA E PRODUÇÃO ORGÂNICA}

Para apoiar o movimento de transição para uma agricultura sustentável, é necessária uma base científica. Essa base é a Agroecologia, definida como: ciência ou disciplina científica que apresenta uma série de princípios, conceitos e metodologias para estudar agroecossistemas. Essa base tem o propósito de permitir a implantação e o desenvolvimento de estilos de agricultura com maiores níveis de sustentabilidade, com dependência mínima de agroquímicos e energia externa, o que permite a regeneração da fertilidade do solo, e a manutenção da produtividade e da proteção das culturas (ALTIERI, 2012).

Do ponto de vista acadêmico, a agroecologia tem caráter multidisciplinar e promove o desenvolvimento rural sustentável. Ela precisa ser entendida como um conjunto de conhecimentos que nos auxilia na análise crítica da agricultura convencional. Ela também orienta o correto redesenho e o adequado manejo de agroecossistemas na perspectiva da sustentabilidade (CAPORAL e COSTABEBER, 2002). Do ponto de vista agrícola, a agroecologia se fundamenta em um conjunto de conhecimentos e técnicas que se desenvolvem a partir de agricultores e de seus processos de experimentação. Por isso, enfatiza a importância de comunidades locais inovarem os processos produtivos através de experimentos transmitidos de agricultor para agricultor (ALTIERI, 2012).

Em função desses experimentos, do conhecimento tácito de cada um, da sinergia e da integração entre as pessoas é que muitos agricultores familiares se organizam em cooperativas. Os objetivos são: facilitar a comercialização, promover o desenvolvimento e a inserção social dos cooperados, a inovação no processo produtivo e apoiar o processo de transição agroecológica e as certificações. 
Para Pacífico e Soglio (2010), a proposta agroecológica para a agricultura familiar é a mudança do modelo de produção com ênfase na valorização do desenvolvimento endógeno, o aumento da renda da família, a agregação de valor aos produtos e a adoção de práticas agrícolas ecologicamente adequadas. Por consequência a "agricultura familiar orgânica torna-se um instrumento de promoção de valores sociais e de qualidade de vida no meio rural, com repercussões igualmente importantes sobre a qualidade de vida no meio urbano" (AZEVEDO, SCHMIDT e KARAM, 2011, p.83).

Para complementar esse pensamento, Conejero, Serra e Neves (2007) dissertam que os sistemas orgânicos de produção possuem características de propriedades com gestão familiar, pois:

- Permitem maior emprego de mão-de-obra;

- Têm menor custo no longo prazo;

- Têm maior produção em médio prazo;

- Geram produtos com maior valor agregado;

- Atendem a mercados com maior procura que oferta no momento.

A agricultura orgânica se apresenta como um sistema produtivo que objetiva a autossustentação da propriedade agrícola, os benefícios sociais para o agricultor, o mínimo uso de energias não renováveis na produção, a oferta de produtos saudáveis e a preservação da saúde ambiental e humana, promovendo qualidade de vida. Conejero, Serra e Neves (2007) complementam afirmando que agricultura orgânica é baseada na tecnologia de processos e fundamentada na produção de alimentos que não utilizam defensivos agrícolas e adubos químicos.

Para garantir que um produto seja orgânico, existe a certificação, baseada em documento ou certificado formal em que são transmitidas informações sobre a segurança e origem do produto (HOPPE, BARCELLOS e VIEIRA, 2012). Conforme as mesmas autoras, a certificação orgânica é considerada uma forma de ressaltar a qualidade e a salubridade do processo produtivo, estabelecendo uma relação de confiança entre o produtor e o consumidor. Ademais, a certificação, além de proporcionar maior credibilidade dos consumidores e conferir maior transparência às práticas utilizadas na produção orgânica, conquista novos mercados, inclusive com maior chance de exportação de seus produtos.

No Brasil, a maioria da comercialização de produtos orgânicos, principalmente hortaliças, é realizada por meio da venda direta ou em feiras. A qualidade do alimento é atribuída à ausência de produtos químicos, porém, cada pessoa associa qualidade a um atributo específico.

\section{I QUALIDADE DE PRODUTOS ALIMENTARES}

A palavra qualidade tornou-se sinônimo de alimentação saudável. Ela orienta os sistemas de produção para uma agricultura sustentável e ecologicamente segura, assim obtém produtos inócuos e contribui para a segurança alimentar.

Alimentos com características de qualidade e segurança são as novas exigências requeridas pelos consumidores. Essas reivindicações obrigam produtores a buscarem alternativas de produção para se adaptar às mudanças que estão ocorrendo no sistema agroalimentar. "O consumidor vem atuando de forma decisiva neste cenário de mudanças, exigindo não só alimentos com atributos gastronômicos e nutricionais, mas com qualidade e segurança a eles associadas" (SPERS, 2000, p. 295).

Diversas definições são atribuídas à qualidade. Para Cunha (2007, p. 650) "qualidade é propriedade, atributo ou condição das coisas ou das pessoas capaz de distingui-las das outras e de lhes determinar a natureza". Borrás e Toledo (2006) explicam que o conceito de qualidade pode ser visto sob diferentes métodos utilizados por uma organização para atendimento do conjunto completo das características da qualidade de um processo, produto ou serviço, com valor nominal e suas respectivas tolerâncias. Para complementar essa ideia, Toledo (2001) afirma que a qualidade é vista como propriedade síntese de múltiplos atributos do produto que determinam o grau de satisfação do cliente. O produto envolve também a embalagem, orientação para uso, imagem, serviços pós-venda e outras características associadas ao produto.

A partir das afirmativas acima, pode-se dizer que a qualidade do produto é resultante da interação entre as qualidades do projeto do produto, projeto do processo, de conformação e da qualidade dos serviços associados ao produto (BORRÁS e TOLEDO 2006).

Para facilitar a compreensão da qualidade demandada pelos consumidores, Garvin (2002) propõe a categorização da qualidade de produto em oito dimensões: 
- Desempenho: produto isento de substâncias nocivas à saúde e apto ao consumo humano;

- Qualidades atrativas: embalagem ergonômica para o transporte, dicas de consumo e receitas e enriquecimento com vitaminas;

- Confiabilidade: taxa de falhas por unidade de tempo, sendo o valor máximo da taxa de falhas iguais à quantidade de vezes que um determinado produto agroalimentar foi consumido;

- Conformidade: grau em que o projeto e as características operacionais de um produto estão de acordo com padrões pré-estabelecidos;

- Durabilidade: tempo de vida de prateleira e o tempo de estocagem na casa do consumidor;

- Atendimento: facilidade de troca de um produto agroalimentar;

- Estética: aparência do produto;

- Qualidade percebida: composição nutricional, embalagem, características sensoriais, comerciais e de segurança.

O Código Brasileiro de Defesa do Consumidor assegura, em seu artigo $6^{\circ}$, a proteção aos direitos do consumidor citando a proteção da vida, saúde e segurança contra os riscos provocados por práticas no fornecimento de produtos e serviços considerados perigosos ou nocivos. Em decorrência disso, muitas pessoas começaram a se preocupar com a segurança alimentar e optaram por hábitos de consumo mais saudáveis, dessa forma, migraram para o consumo de alimentos orgânicos.

\subsection{COOPERAÇÃO NA AGRICULTURA}

Com a demanda por alimentos saudáveis, as cooperativas se tornaram canais de comercialização para os produtores, principalmente os de orgânicos, em função de possuir ponto fixo de venda, apoio logístico e auxílio técnico.

A formação de uma cooperativa pode contribuir com o sucesso do setor primário da economia - a agricultura - impulsionando seu desenvolvimento. Para Correia et al., (2011) "é nesse cenário que emergem novas formas de produção baseados na associação, na complementaridade, no compartilhamento, na troca, na colaboração e na ajuda mútua."

Para Neto (2000), as cooperativas são organizações atuantes nos agronegócios como formas eficientes de coordenar as relações de contrato, possibilitando a redução de riscos para o produtor e a agregação de valor. Em outras palavras, essas associações promovem o desenvolvimento agrícola. Buttenbender (2010) complementa, afirmando que a cooperação considera todas as práticas que ocorrem entre os diferentes níveis e elos da cadeia do agronegócio.

O crescimento das estruturas cooperativas é seguido pelo aumento da complexidade de sua gestão (ZYLBERSZTAJN, 1994). Os gestores de associações e/ou cooperativas têm o desafio de satisfazer as exigências dos consumidores, oferecendo produtos de qualidade. Muitas vezes, unem-se com outros tipos de parceiros como: competidores, universidades, consultores, institutos de pesquisa e tecnologia para adquirirem conhecimento e, dessa forma, produzirem o quê e como exigem seus consumidores (SANTINI et al., 2006).

\section{METODOLOGIA}

Esta seção do artigo apresenta objeto do estudo, sua caracterização e os procedimentos metodológicos utilizados para sua execução.

\section{I OBJETO DO ESTUDO}

A Feira da Agricultura Ecológica teve início em 1989 e está localizada em vários pontos comerciais de Porto Alegre. Ela é considerada pioneira na comercialização de produtos orgânicos na capital e no estado do Rio Grande do Sul. A feira é organizada pela Secretaria Municipal da Produção, Indústria e Comércio (SMIC). Os pontos de venda dispõem de diferenciados produtos orgânicos, tanto in natura como agroindustrializados, procedentes do Cinturão Verde de Porto Alegre e municípios vizinhos, localizados até 200 quilômetros da capital. O diferencial é vender alimentos orgânicos e oferecer produtos que são comercializados diretamente pelos produtores rurais (Prefeitura Municipal de Porto Alegre, 2012).

Para esse estudo, a população alvo foi composta por todos os agricultores que, especificamente, 
produziam hortaliças e participavam da Feira Ecológica da Redenção. A feira ocorre no município de Porto Alegre, no estado do Rio Grande do Sul.

\subsection{CARACTERIZAÇÃo Do ESTUdo}

De acordo com os resultados almejados, o presente estudo é categorizado como social-empírico e, segundo sua tipologia, enquadra-se em uma pesquisa aplicada (DORNELLES, 2006).

Esta pesquisa é aplicada e se classifica como exploratória (RICHARDSON, 1999). O instrumento para coleta de dados foi elaborado em modo de entrevista estruturada, com perguntas abertas e fechadas, conduzidas pelo observador. Tal abordagem da realidade caracteriza a origem dos dados como fonte primária (KERLINGER, 1980).

\subsection{Procedimentos de Coleta e tratamento dos dados}

A população de agricultores de hortaliças possui, aproximadamente, 35 produtores que atendiam às especificações estabelecidas para o estudo. Tal número de integrantes é um valor aproximado, pois é resultante de uma contagem presencial, visto que o acesso ao registro formal dos participantes desta feira não foi disponibilizado. Neste sentido, a realização de um censo ficaria prejudicada devido às limitações burocráticas.

Definida a população, frente à limitação de fazer um censo, procurou-se alcançar a maior parcela compreensível de elementos, ou seja, estabelecer uma amostra. Tal amostragem foi não probabilística, posto que calcular a probabilidade de cada elemento não fazia parte dos objetivos do estudo. Assim, a amostra foi casual (SELLTIZ et al., 1975) e constou de 27 entrevistados. A disposição em participar do estudo foi o fator de inclusão. Duas das 27 entrevistas foram desconsideradas pelos pesquisadores, uma vez que os respondentes foram identificados como funcionários da equipe de vendas e não dispunham dos conhecimentos técnicos necessários para fornecer respostas válidas para este estudo. Dessa maneira, restaram 25 entrevistas para análise, cuja tabulação foi feita utilizando a ferramenta Microsoft Excel® 2007.

O tratamento dos dados foi realizado a partir do procedimento de abordagem quantitativa e qualitativa. Para análise qualitativa, optou-se pela análise de conteúdo como técnica empregada para interpretar tais dados. Para Bardin (2008), por meio desta técnica é possível analisar mensagens, utilizando-se de procedimentos sistemáticos e objetivos, concernentes ao processo de comunicação.

O roteiro da entrevista apresentou a seguinte estrutura: nove questões para fins de identificação do respondente e oito perguntas abertas que abordaram as respectivas técnicas empregadas nos processos produtivos e as percepções de cada agricultor. As informações coletadas geraram um banco de dados. Tal base foi utilizada para comparar as percepções dos produtores de diferentes localidades, presentes na feira. Dessa maneira, seguindo o alerta de Richardson (1999), a condução da análise de conteúdo prestou a devida atenção a cada palavra empregada.

\section{RESULTADOS E DISCUSSÃO}

\section{I Perfil dos feirantes}

A maioria dos feirantes (92\%) eram homens, no entanto, em diversos espaços de comercialização pode-se observar a presença do casal na organização dos produtos e no atendimento ao cliente. Entre eles, predomina a faixa etária de 41 a 50 anos de idade. De acordo com o relato anterior, os agricultores possuem suas unidades produtivas em Porto Alegre e municípios vizinhos (80\%) próximos.

\subsection{ESTRUTURA E ORGANIZAÇÃO DAS UNIDADES PRODUTIVAS}

$\mathrm{Na}$ Tabela 1 são apresentados os resultados quanto à gestão das propriedades.

Entre os sete agricultores do grupo que utilizam mão de obra contratada, esta é, na maioria dos casos, eventual e especificamente para a colheita ou contratação de serviços como máquinas para a preparação do solo. Os feirantes destacaram a dificuldade de conseguir mão de obra para o cultivo de hortaliças, além do alto custo para manter os empregados. Sendo assim, produzem em menor escala e utilizam somente a mão de obra disponível no grupo familiar que é composto, em média, por quatro pessoas e em torno de três trabalham na atividade. As pessoas que não trabalham na atividade são crianças em idade escolar que, esporadicamente, contribuem no cultivo e/ou organização das feiras. 
Em geral, constituem-se de pequenas unidades produtivas, de posse dos agricultores, predominando o cultivo em uma área de até cinco hectares de terra.

Tabela 1 - Estrutura das propriedades.

\begin{tabular}{l|c|c}
\hline \hline \multicolumn{1}{c|}{ Questões } & Sim & Não \\
\hline $\begin{array}{l}\text { A gestão da propriedade é feita pelo } \\
\text { agricultor? }\end{array}$ & 25 & 0 \\
$\begin{array}{l}\text { Utiliza mão de obra contratada? } \\
\begin{array}{l}\text { Pertence a alguma cooperativa ou } \\
\text { associação? }\end{array}\end{array}$ & 22 & 18 \\
\hline \hline $\begin{array}{l}\text { A propriedade pertence à família ou é } \\
\text { arrendada? }\end{array}$ & Própria & Arrendada \\
\cline { 2 - 3 } & 24 & 1 \\
\hline \hline
\end{tabular}

Fonte: dados da pesquisa (2012).

Os feirantes recebem apoio técnico das respectivas certificadoras e cooperativas, bem como da Embrapa, Emater e SMIC. Outra prática identificada é a cooperação entre os próprios agricultores, que trocam experiências e conhecimentos técnicos, uma vez que alguns possuem curso superior em áreas afins.

Dos 25 agricultores, somente três não estão vinculados a alguma associação ou cooperativa, sendo que 32\% do grupo pertencem à Cooperativa Arco-íris e 44\% à Associação dos Agricultores Ecologistas. Muitos feirantes estão vinculados a outras associações ou cooperativas estabelecidas nos seus municípios de origem. Entre elas, destacam-se: Associação Grupo GESA, APEVS - Associação Produtores Ecológicos de Vila Segredo, Cooperativa Econativa, COCEARGS - Cooperativa Central dos Assentados do RS, AECIA - Associação de Agroecologistas de Ipê e Antônio Prado e ASTRASUL - Associação de Cerro Grande do Sul. Para Buttenbender (2010), cooperativas são associações autônomas de pessoas que se unem de forma voluntária. Dessa maneira, satisfazem aspirações e necessidades econômicas, sociais, ambientais e culturais comuns, por meio de uma organização de propriedade coletiva e democraticamente gerida.

Quanto à comercialização dos produtos orgânicos, $44 \%$ dos produtores rurais vendem a produção somente nesta feira específica. Entretanto, um número significativo de agricultores, representando $56 \%$, possuem alternativas diversificadas. Eles vendem os produtos orgânicos em outros pontos comerciais como: algumas feiras em Porto Alegre e região, supermercados, restaurantes, venda ao consumidor diretamente na propriedade e em lojas de produtos naturais. Além disso, destacam-se dois produtores: um deles fornece alimentos orgânicos para a merenda escolar e o outro comercializa seus produtos nos estados de Minas Gerais, São Paulo e Rio de Janeiro. Nesse sentido, ocorre a difusão de novos valores na comunidade e também o acesso a mercados de centros consumidores de maior porte (PELEGRINI e GAZOLLA, 2008). Assim, de modo orientado, elas vão ajustando-se à economia (WILKINSON, 2008). Devido a essa condição, algumas cooperativas agropecuárias instituíram canais próprios de comercialização.

Entre os principais produtos comercializados pelos feirantes, destaca-se a oferta de alface em $80 \%$ das bancas, seguindo como o radiche em 17 bancas, beterraba em 11 bancas, abobrinha e cebola em nove bancas, alho poró, berinjela, cenoura, ervilha e rabanete em oito bancas. Essas são as hortaliças mais comuns entre as bancas, no entanto, os feirantes oferecem, em média, oito tipos diferentes de hortaliças orgânicas, ressaltando que alguns dispõem de outros produtos orgânicos.

\subsection{PráticAs de MANejo NA PRODUÇão de HORTALIÇAS ORGÂNICAS}

Os agricultores foram questionados quanto à utilização de inseticidas, herbicidas e adubação do solo para o cultivo de hortaliças orgânicas. Quanto aos cuidados e adubação do solo, três agricultores mencionaram que fazem a rotação de cultura, quatro fazem a correção do solo com o uso de calcário 
e 23 utilizam compostos orgânicos (biomassa e esterco) e dois agricultores dizem não utilizar nenhum tipo de controle. Ressalta-se que essas técnicas são utilizadas conjuntamente pelos agricultores, ou seja, eles podem utilizar composto orgânico + calcário + rotação de cultura. Esse movimento é o resultado da busca de uma rápida adequação à crescente diversificação da demanda, o que exige um processo de inovação contínua para customizar equipamentos, embalagens, insumos e sistema produtivo (CHRISTENSEN, RAMA e VON TUNZELMANN, 1996; GALIZZI e VENTURINI, 1996).

Além da fertilização do solo, destaca-se a necessidade do controle de ervas. De acordo com a maior parte dos entrevistados, as ervas podem permanecer junto ao cultivo das hortaliças, retirando somente os excessos. Essa retirada geralmente é feita manualmente. Apenas dois feirantes mencionaram que utilizam bio-herbicidas, aprovados e recomendados pela certificadora de produtos orgânicos.

Existem quatro principais pragas que atacam as hortaliças: lagarta, pulgão, cascudinho e joaninha. Para manter o controle sobre esses invasores, os produtores agrícolas utilizam algumas técnicas de controle biológico e produtos considerados inofensivos à saúde dos próprios agricultores e dos consumidores dos produtos orgânicos. Assim, os principais produtos utilizados na produção são: calda de fumo e da casca da uva, pimenta diluída na água e cinzas. Um dos feirantes mencionou que alimenta as formigas, no formigueiro, com calda de laranja. Dessa maneira elas permanecem no formigueiro e não atacam as hortaliças.

Além disso, a técnica de manter as ervas entre as hortaliças contribui para o controle dos insetos. Dois agricultores relataram que plantam picão branco e outras ervas para os insetos se alimentarem. Outro fator, citado pelos agricultores, é a observância da época apropriada para o plantio de determinadas culturas, considerando as condições climáticas mais favoráveis para cada produto. Com isso, ressalta-se que a oferta de hortaliças para comercialização na feira varia de acordo com as condições climáticas e com o período apropriado para seu cultivo.

\subsection{QUALIDADE E CERTIFICAÇÃO: PERCEPÇÃO DOS FEIRANTES}

Os feirantes foram questionados quanto à qualidade e certificação dos produtos orgânicos. Dos 25 produtores participantes da pesquisa, 23 deles possuem algum tipo de certificação orgânica. A certificação é baseada em documento formal, em que são transmitidas informações sobre a segurança e origem do produto (HOPPE, BARCELLOS e VIEIRA, 2012). Conforme as mesmas autoras, a certificação orgânica é considerada uma forma de ressaltar a qualidade do salubridade do processo produtivo, estabelecendo uma relação de confiança entre o produtor e o consumidor. Alguns possuem mais que uma certificação concomitantemente. Predomina a certificação participativa Ecovida com 15 certificações, seguidas pela Ecocert com três certificações e a OCS, também com três certificações. Dois feirantes mencionaram que possuem certificação orgânica, no entanto não as nominaram. Um produtor está em processo de obtenção da certificação Ecovida, e outro não possui nenhuma, alegando que "o melhor certificado é o consumidor", ou seja, na sua percepção quem definirá se o produto possui qualidade ou não é o consumidor.

Destaca-se que os agricultores que possuem a certificação Ecocert, alegaram dificuldades para mantê-la devido ao alto custo.

De acordo com o MAPA - Ministério da Agricultura, Pecuária e Abastecimento (2012), a principal característica da produção orgânica "é não utilizar agrotóxicos, adubos químicos ou substâncias sintéticas que agridam o meio ambiente". Diante disso, obteve-se, também, o entendimento sobre os motivos que levaram os agricultores a adotarem esse modelo de cultivo orgânico e a percepção de qualidade atribuída a uma hortaliça.

As respostas referentes aos motivos que levaram os produtores a adotar este tipo de produção estão expostas na figura 1. Para cada grupo foram destacadas algumas das respostas obtidas nas entrevistas.

Diversos motivos levaram os feirantes a produzir hortaliças orgânicas. O agrupamento clima e solo ressalta a viabilidade da produção e a garantia de renda contínua aos agricultores. A interação clima-solo condiciona as técnicas e as práticas dos sistemas de cultivo e de criação (LIMA et al., 2005). Isso se deve ao ciclo curto de produção e possibilidade de diversificação de cultura nas diferentes estações do ano, sendo que o agricultor não se limita ao cultivo de um produto específico. Para Araújo (2005), o clima condiciona a implantação e o manejo da maioria das culturas agropecuárias. Ademais, determina épocas de plantio, tratamentos, colheitas, escolha de espécies, vegetais e animais. O solo também participa diretamente do ciclo produtivo, pois suas condições químicas, físicas, biológicas e topográficas determinam sua fertilidade. 


\begin{tabular}{|c|c|c|}
\hline Agrupamentos & Frequência & Destaque para algumas respostas dos feirantes \\
\hline \multirow{3}{*}{ Saúde } & \multirow{3}{*}{7} & "Pensando no bem estar da família e dos consumidores". \\
\hline & & "Evitar o risco de intoxicação com agrotóxicos". \\
\hline & & $\begin{array}{l}\text { "Uma produção sem agrotóxicos, pensando no bem estar e } \\
\text { saúde". }\end{array}$ \\
\hline \multirow{3}{*}{ Comércio } & \multirow{3}{*}{6} & "Diversificação de produtos para o consumidor." \\
\hline & & "Porque gosta e dá retorno financeiro". \\
\hline & & "Demanda por produtos ecológicos". \\
\hline $\begin{array}{l}\text { Mão de obra } \\
\text { familiar }\end{array}$ & 3 & $\begin{array}{l}\text { "Porque é possível produzir mais em pouca terra e utiliza a } \\
\text { mão de obra familiar". }\end{array}$ \\
\hline \multirow{3}{*}{ Clima e solo } & \multirow{3}{*}{9} & "Solo e clima, produzindo tudo no período certo". \\
\hline & & "Por causa do ciclo curto". \\
\hline & & "Mais rápido para cultivar". \\
\hline
\end{tabular}

Figura 1 - Motivos que levaram os agricultores a produzir hortaliças orgânicas Fonte: dados da pesquisa (2012).

Outro fator que merece destaque é a preocupação dos agricultores com os cuidados referentes à saúde da família e dos consumidores das hortaliças. O fator mercado também é representativo na opinião dos agricultores. Para Valent (2014), esse resultado demonstrou que, além da preocupação com a saúde, os cooperados também associam a produção orgânica com maior renda.

O sistema orgânico referenciado neste trabalho está associado à utilização da mão de obra familiar para otimizar a produção em um espaço menor de terra.

$\mathrm{Na}$ Tabela 2 são apresentadas algumas percepções de qualidade dos agricultores referentes a produção de hortaliças:

Tabela 2 - Qualidade das hortaliças na percepção dos agricultores.

\begin{tabular}{|c|c|c|}
\hline Agrupamentos & Frequência & Destaque a algumas das respostas dos feirantes \\
\hline \multirow[t]{2}{*}{ Boa aparência } & \multirow[t]{2}{*}{5} & $\begin{array}{l}\text { "Limpeza, boa aparência, capricho e cuidado no } \\
\text { transporte". }\end{array}$ \\
\hline & & $\begin{array}{l}\text { "Boa aparência, com sabor, bom tamanho e sem } \\
\text { contaminantes químicos e orgânicos". }\end{array}$ \\
\hline \multirow[t]{2}{*}{ Orgânica } & \multirow[t]{2}{*}{15} & "Uma hortaliça orgânica é de boa qualidade". \\
\hline & & $\begin{array}{l}\text { "Orgânica, sabor, tamanho e aparência". } \\
\text { "Produzida num ambiente limpo". } \\
\text { "Pura, natural". } \\
\text { "Que não tenha agrotóxico". }\end{array}$ \\
\hline \multirow[t]{2}{*}{ Solo } & \multirow[t]{2}{*}{2} & $\begin{array}{l}\text { "Qualidade se obtém com um solo bem corrigido, boa } \\
\text { irrigação e limpeza". }\end{array}$ \\
\hline & & "Produzida num solo bem preparado". \\
\hline \multirow[t]{2}{*}{ Outros } & \multirow[t]{2}{*}{3} & "Produzir com amor, gostar do que faz". \\
\hline & & $\begin{array}{l}\text { "Que coma e te dê prazer, confiança do consumidor no } \\
\text { produtor". }\end{array}$ \\
\hline
\end{tabular}

Conforme ilustrado na tabela 2, quando perguntados sobre o que era uma hortaliça de qualidade, observa-se que 13 dos agricultores mencionaram que qualidade está fortemente vinculada às características da produção orgânica, ou seja, isento de agrotóxicos. No geral, percebe-se uma limitação quanto à visão de todo o processo, que vai desde o preparo do solo, produção, colheita, armazenagem, transporte e comercialização do produto. As respostas se limitam a uma ou duas fases do processo, no entanto, percebe-se que a soma de todas essas percepções pode gerar um conceito mais adequado 
para definir o que é uma hortaliça de qualidade.

Borrás e Toledo (2006) explicam que o conceito de qualidade pode ser visto sob várias maneiras. Pode ser utilizado por um produtor ou organização para atender ao conjunto de características da qualidade de um processo, produto ou serviço, com valor nominal.

Assim, empregando a visão dos produtores rurais sobre qualidade das hortaliças, infere-se que essa qualidade inicia com o preparo adequado do solo e boa irrigação, produção isenta de agrotóxicos, colheita e armazenagem dos produtos num ambiente limpo e sem contaminantes, transporte adequado da unidade de produção até o ponto de venda. Ou seja, qualidade pode ser considerada a soma de todos os atributos destacados na Tabela 2.

\section{CONCLUSÕES}

Foi possível constatar que os padrões de qualidade adotados pelos agricultores orgânicos estão alicerçados à obtenção de certificação orgânica. Assim, para a maioria dos produtores rurais, uma hortaliça de qualidade não utiliza agrotóxicos, adubos químicos ou substâncias sintéticas.

A agricultura orgânica da Feira tem característica de agricultura familiar, pois as famílias são gestoras das unidades produtivas, o trabalho empregado na produção é, em maior parte, mão de obra familiar e as propriedades não ultrapassam os quatro módulos rurais (FAO/INCRA, 1996). Percebe-se que alguns agricultores confundem agricultura familiar com produção orgânica quando afirmam que ambas são correspondentes. Isto pode ser em função da produção em pequena escala.

Do total de entrevistados, 22 pertencem à cooperativas e prestam assessoria a si próprios, pois alguns possuem curso superior na área agrícola. A cooperação pode estimular a produção orgânica, pois a troca de conhecimento e experiência fortalece esta prática.

A resposta "clima e solo" foi o motivo principal para produção de hortaliças orgânicas. Os agricultores observam esses fatores, pois são fundamentais para garantir boa aparência ao alimento, atribuindo-lhe qualidade. É natural que o fato de ser orgânico garanta a qualidade das hortaliças, pois parte-se do pressuposto que somente os cuidados no cultivo garantem esta qualidade.

Portanto, o fato de ser orgânico é uma característica que garante a qualidade da hortaliça para os agricultores. Salienta-se que cuidados devem ser tomados desde a preparação do solo, cultivo, transporte e disposição dos produtos no ponto de venda.

\section{REFERÊNCIAS}

ALTIERI, Miguel. Agroecologia: bases científicas para uma agricultura sustentável. 3 ed. São Paulo, Rio de Janeiro: Expressão Popular, AS-PTA, 2012.

ANDRIOLI, Antônio Inácio. Oportunidades e desafios da agroecologia para a agricultura familiar. In: DALLABRIDA, V. R.; BÜTTENBENDER, P. L. (Org.). Gestão, Inovação e Desenvolvimento: oportunidades e desafios para o desenvolvimento da região Fronteira Noroeste. Santa Cruz do Sul: Edunisc, 2007.

ARAÚJO, Luiz Carlos de. O administrador rural nas suas tomadas de decisões. Agronline, 12 ago. 2005. Disponível em: <http://www.agronline.com.br/artigos/o-administrador-rural-nas-suas-tomadas-decisoes>. Acesso em: 31 mar. 2013.

AZEVEDO, Elaine de; SCHMIDT, Wilson; KARAM, Karen Follador. Agricultura familiar orgânica e qualidade de vida. Um estudo de caso em Santa Rosa de Lima, SC, Brasil. Revista Brasileira de Agroecologia, Cruz Alta, v. 6, n. 3, p. 81-106, 2011.

BARDIN, Lawrence. Análise de conteúdo. Lisboa: Edições 70, 2008.

BORRÁS, M. A. A.; TOLEDO, J. C. Qualidade dos produtos agroalimentares: a importância da gestão da qualidade no agronegócio. In: ZUIN, L. F. S.; QUEIROZ, T. R. (Coords.). Agronegócios: Gestão e Inovação. São Paulo: Saraiva, 2006, p. 189 - 218. 
BRASIL. Lei nº 8.078 de 11 de setembro de 1990. Dispõe sobre a proteção do consumidor e dá outras providências. Brasília - DF, 11 set. 1990. Disponível em:

<http://www.planalto.gov.br/ccivil_03/leis/L8078.htm >. Acesso em: 18 nov. 2012.

BUTTENBENDER, P. L. O Agronegócio Cooperativo. In: SPAREMBERGER, A.; BUTTENBENDER, P. L.; ZAMBERLAN, L. Princípios de Agronegócios: conceitos e estudos de casos. Ijuí: Unijuí, 2010, p. 71-98.

CAPORAL, F. R.; COSTABEBER, J. A. Conceitos de Agroecologia. Revista de Agroecologia e Desenvolvimento Rural Sustentável, Porto Alegre, v. 3, n. 2, p. 13-16, 2002.

CHRISTENSEN, J. L.; RAMA, R.; VON TUNZELMANN, N. G. Innovation in the european food products and beverage industry. Industry studies of innovation using C.I.S. data. Bruxelles (BEL): European Commission - EIMS Project 94/111 EIMS, 1996. (Publication, $\mathrm{n}^{\circ}$ 35).

CONEJERO, M. A.; SERRA, L.; NEVES, M. F. Produtos Orgânicos: o que é, dimensões e como se habilitar. In: NEVES, Marcos Fava (Coord.). Agronegócios e Desenvolvimento Sustentável: uma agenda para a liderança mundial na produção de alimentos e bioenergia. São Paulo: Atlas, 2007, p. 90-101.

CORREIA, A. M. M. et al. Análise qualitativa das práticas de cooperação em uma associação agrícola de produtos orgânicos na percepção dos associados. Revista Brasileira de Agroecologia, Cruz Alta, v. 6, n. 1, p. 147-162, 2011.

CUNHA, Antônio Geraldo da. Dicionário etimológico da língua portuguesa. 3 ed. Rio de Janeiro: Lexikon, 2007.

DORNELLES, Geni de Sales. Metagestão: a arte do diálogo nas organizações. São Paulo: Saraiva, 2006.

FAO/INCRA. Perfil da agricultura familiar no Brasil: dossiê estatístico. FAO/INCRA: Projeto UFT/ BRA/036/BRA, 1996.

GALIZZI, G.; VENTURINI, L. Product innovation in the food industry: nature, characteristics and determinants. In: GALIZZI, G.; VENTURINI, L. (Ed.). Economics of innovation: the case of food industry. Heidelberg (Alemanha): Physica Verlag, 1996.

GARVIN, D. A. Gerenciando a qualidade: a visão estratégica e competitiva. Rio de Janeiro: Qualitymark, 2002.

HOPPE, A.; BARCELLOS, M. D.; VIEIRA, L. M. Comportamento do consumidor de produtos agroalimentares orgânicos. In: DORR, A. C.; ROSSATO, M. V.; ZULIAN, A. Agronegócio: panorama, perspectivas e influencia do mercado de alimentos certificados. Curitiba: Appris, 2012, p. 49-70.

KERLINGER, Fred Nichols. Metodologia da pesquisa em ciências sociais. São Paulo: Editora Pedagógica e Universitária, 1980.

LIMA, A. P. et. al. Administração da unidade de produção familiar: modalidades de trabalho com agricultores. 3. ed. Ijuí: Editora Unijuí, 2005.

NETO. Sigismundo Bialoskorski. Agribusiness Cooperativo. In: ZYLBERSZTAJN, D.; NEVES, M. F. (Org.). Economia e Gestão dos Negócios Agroalimentares. São Paulo: Pioneira, 2000, p. 235 - 253.

PACÍFICO, Daniela A.; SOGLIO, Fábio K. D. Transição para agricultura de base ecológica: um processo social. Revista Brasileira de Agroecologia, Cruz Alta, v. 5, n. 2, p. 50-64, 2010.

PELEGRINI, G.; GAZOLLA, M. A Agroindústria Familiar no Rio Grande do Sul: Limites e Potencialida- 
des a sua Reprodução Social. Frederico Westphalen/RS: Ed. da URI, 2008.

RICHARDSON, Roberto Jarry. Pesquisa social: Métodos e técnicas. São Paulo: Atlas, 1999.

SANTINI, G. A.; et al. Conceitos de Inovação no Agronegócio. In: ZUIN, L. F. S.; QUEIROZ, T. R. (Coords.). Agronegócios: Gestão e Inovação. São Paulo: Saraiva, 2006, p. 219 - 250.

SELLTIZ, C.; JAHODA, M.; DEUTSCH, M.; COOK, S. W. Métodos de pesquisa nas relações sociais. São Paulo: EDUSP, 1975.

SPERS, Eduardo Eugênio. Qualidade e Segurança em Alimentos. In: In: ZYLBERSZTAJN, D.; NEVES, M. F. (Org.). Economia e Gestão dos Negócios Agroalimentares. São Paulo: Pioneira, 2000, p. 283-321.

TOLEDO, J. C. de. Gestão da qualidade na agroindústria. In: BATALHA, M. O. (Org.). Gestão agroindustrial. 2 ed. São Paulo: Atlas, 2001, v.1, p.472.

VALENT, Joice Zagna. O Processo Decisório na Transição Agroecológica dos Agricultores da Cooperativa Leoboqueirense de Agricultores Familiares. 2014. 98 f. Dissertação (Mestrado em Agronegócios) - Centro de Estudos e Pesquisas em Agronegócios, Universidade Federal do Rio Grande do Sul, Porto Alegre, 2014.

WILKINSON, J. Mercados, redes e valores: o novo mundo da agricultura familiar. Porto Alegre: Editora da UFRGS, 2008.

ZYLBERSZTAJN, Decio. Organização de cooperativas: desafios e tendências. São Paulo: PENSA-FEA-USP, 1994. 